\title{
The role of academic leagues as a strategy for pain education in Brazil
}

This article was published in the following Dove Press journal:

Journal of Pain Research

\section{João Batista Santos Garcia José Osvaldo Barbosa Neto Thiago Alves Rodrigues}

Experimental Laboratory to the Study of Pain, Federal University of Maranhão, São Luis, Maranhão, Brazil
Correspondence: João Batista Santos Garcia

Avenida Ivan Loureiro, 745. Apto 70I. Ponta d'areia, São Luis, Maranhão 65077 556, Brazil

Tel +5 5988020622

Email jbgarcia@uol.com.br
Purpose: Chronic pain remains undertreated in both developed and developing countries. There are various factors involved in this acknowledged health problem, including lack of pain education. In Brazil, a particular approach was used to mitigate the deficit in pain education. The academic leagues of pain (ALPs) were formed as associations of health undergraduate students with the goal of encouraging students in educational activities, patient care, and pain research. The aim of this study was to evaluate how ALP works and its contribution to pain education and to the inclusion of students in practical and scientific research activities, as well as its legacy in the field of pain.

Patients and methods: An electronic survey was directed to the leagues representatives to collect data referent to how the leagues operate, their individual approach towards pain education, patient care, research activities, and its impact on students after they graduate.

Results: A total of 17 leagues were identified and responded to the survey. Only three of the involved universities offered study of pain as a discipline in their mandatory curriculum. Patient care activities were carried out by $59 \%$ of the leagues, $94 \%$ provided educational activities. Twelve leagues reported that students were involved in one to four research projects in pain, and $59 \%$ of those chose pain as their subject for post-graduation programs. And, $47 \%$ of the leagues had students that sought specialization or residency in pain after graduation.

Conclusion: The Brazilian experience with academic leagues of pain has shown that it is possible to address curricular deficiencies in pain education through a strategy not well known in other countries.

Keywords: medical education, pain education, pain management, chronic pain

\section{Introduction}

Inadequate treatment of chronic pain remains a public health problem, both for developed and for developing countries, being one of the main factors responsible for the loss of ability to work, increased costs for public health systems, and, mainly, loss of patient quality of life. ${ }^{1-5}$

In Brazil, chronic pain prevalence was 39\%, and dissatisfaction with treatment was reported by $49 \%$ of the pain patients that were interviewed in a populationalbased survey. ${ }^{6}$ Chronic pain is also common in Latin America countries, but prevalence in this region is currently unknown, due to lack of epidemiological study. $^{7}$ The USA, a developed country, also struggles with a $20 \%$ prevalence of chronic pain. In addition to that, $8 \%$ of the USA adult population presents with limited life or work activities on most days. ${ }^{8}$

Developing countries face particular barriers to improving care for chronic pain patients, such as the low availability and high cost of analgesics, the lack of government 
policies dedicated to these patients, and limited resources for the establishment of specialized pain treatment services. In a study that interviewed members of the International Association for the Study of Pain (IASP) in developing countries, lack of pain education and government policies, fear of opioid addiction, high cost of analgesics, and low patient adherence were cited as the main obstacles to pain treatment. ${ }^{9}$ Among these barriers, the lack of education was mentioned by $91 \%$ of respondents, underscoring its significance in developing countries. ${ }^{9}$ The percentage of medical schools that offer pain content and the amount of information that is provided to students is currently unknown in our country, due to lack of studies focusing on this matter. However, a survey-based study in Brazil shows that $76 \%$ of the students feel that they did not receive enough information to deal with patient in pain, and pain was not offered as a specific discipline to $80 \%$ of the responders. ${ }^{10}$

For more than a decade, the IASP has been working to reduce the negative impact of the lack of pain education through funding and training programs for developing countries. ${ }^{9}$ However, the impact of these programs on patient care is not yet known. The Brazilian Chapter of IASP, the Brazilian Society to the Study of Pain (SBED), started in 2018 a national program to improve pain management. In this initiative, SBED proposes actions to reduce undertreatment, to perfect evaluation, and to monitor the quality of pain treatment. SBED proposes some actions to accomplish these goals, such as the implementation of pain education in medical schools, including its physiopathology and management, and also the strengthening of scientific research programs in university hospitals. ${ }^{11}$

Parallel to the efforts of the IASP and SBED, for several years, students and professors in Brazilian universities have been spontaneously and independently forming student groups dedicated to the study of pain as a way of complementing the deficiencies in their curricula. These associations are known as academic league of pains (ALP), and this initiative has been replicated throughout the country. ${ }^{12-14}$ Conceptually, these leagues are formed by students and professors of different healthcare fields, who unite to develop scientific research, and promote didactic and health promotion activities, thereby strengthening academic training. The leagues are established within academic departments of the respective universities and are coordinated by a professor. Their activities are regulated by bylaws, which must contain the objectives, purposes, disciplinary code, and obligations of the coordinating professors, students, and other members. ${ }^{15}$
Participants in the academic pain league engage in both theoretical and practical training, including training on patient care under the guidance of a pain specialist, through outreach health care programs. This initiative strengthens teaching and brings students closer to research and health care activities, the bases of the construction of scientific knowledge in an institution of higher education. ${ }^{13,14}$ Historically, since ALP was not a formal program of Brazilian universities, to provide institutional linkage to universities and to be eligible for grants and funding, these student associations were registered as outreach (also known as "extension") programs, a formally recognized initiative by universities in Brazil.

The aim of the present study was to evaluate how ALP works and its contribution to pain education and to the inclusion of students in practical and scientific research activities, as well as its legacy in the field of pain.

\section{Materials and methods}

We conducted an observational descriptive retrospective study through an electronic based survey distributed by email to representatives of ALPs between November 2017 and March 2018. The subjects of this study were identified from the website of the Brazilian Society for the Study of Pain (Sociedade Brasileira para Estudo da Dor - SBED), the Brazilian chapter of the IASP, as well as through an active search on the websites of the main public and private Brazilian universities.

As the present study focused on data belonging to academic institutions, not on information collected from human beings, it was waived from processing by the ethics committee, according to Resolution 510 of the National Health Council/Brazil (2016). Nevertheless, informed consent was sent as the first page of the questionnaire, where the subject agreed to participate in the research and provide physical signature, if necessary.

The construction of the questionnaire focused on the acquisition of relevant information on the functioning of the leagues, as well as on the way in which important aspects of medical education were approached. It consisted of 14 objective questions divided between the operation of the leagues, the participation in care-related activities, engagement in scientific initiation projects, and in postgraduate programs. After the questionnaire was finalized, a pilot test of the survey was done among doctors and nurses that collaborate with one of the selected leagues. In this trial, matters of content, writing, and system functionality were observed by the voluntaries. The feedback provided 
was then discussed between the research team and applied to the original text if necessary (Table 1).

SurveyMonkey Inc. (San Mateo, California, USA; www.surveymonkey.com) was used to develop and distribute the questionnaires, and a database was constructed with the answers obtained. A reminder was scheduled to be sent within a week of the first e-mail. If a response was not received by the researchers after this time, a phone call to was made as a final reminder.

\section{Operation of the leagues}

The first nine questions were dedicated to the operation of the leagues and the integration between league activities and the academic training of the participants. The following information was collected: the number of participants of each league, affiliated universities, existence of teaching activities, hours dedicated to theoretical activities and the perception of retention of knowledge, as well as whether these activities are complementary to an existing curricular program at the affiliated university. This section aims to build an overall understanding of the situation of pain education in Brazil and how the leagues work to fill the gaps in the curriculum.

\section{Care-related activities (university outreach projects) and research}

The care-related activities developed through university outreach projects developed by the leagues may be carried out in several formats, and two questions addressed this aspect. These projects are considered as one of the three pillars to medical education, along with teaching and research. They consist of specific health care programs that promote medical assistance to a population, and at the same time, provide environment to supervised medical training of students and the construction of database to scientific research.

The involvement of academic league participants in research activities was specifically addressed in the questionnaire in two other questions. Research is also a fundamental pillar of medical education in Brazilian universities, and these questions have been elaborated to understand the role of leagues in initiating students in this field.

\section{Legacy of the leagues}

The last two questions were designed to understand the legacy left to pain field after students' participation in ALP. This legacy was defined here as students that chose

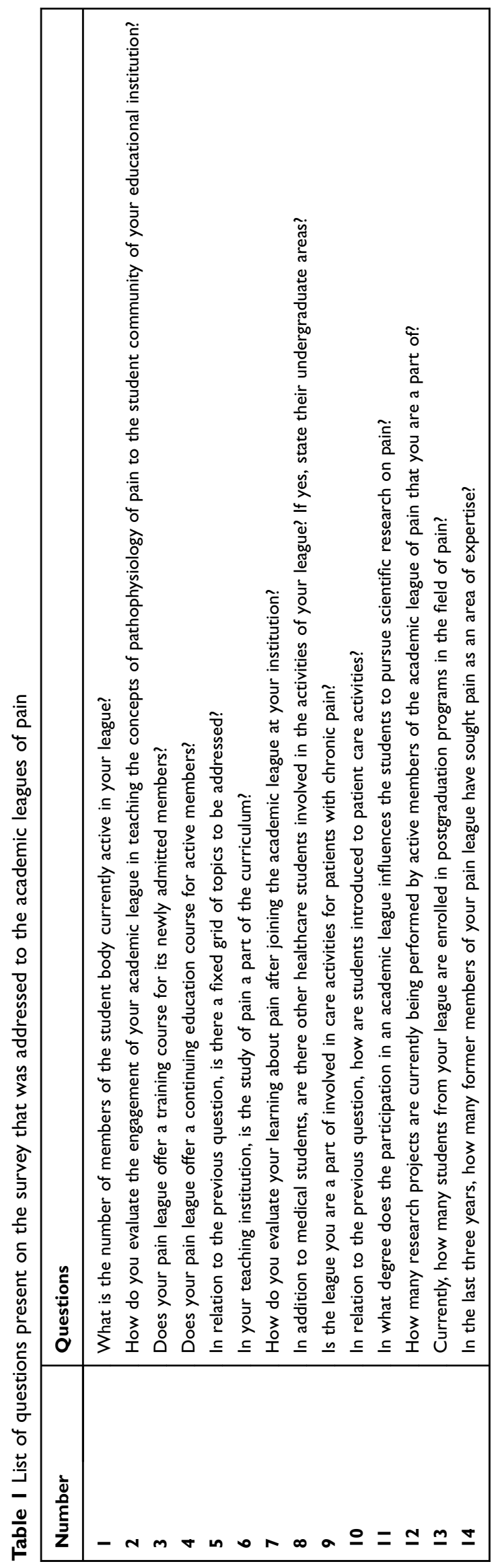


to work with pain patients or were enrolled in postgraduation programs. For this purpose, we constructed questions specifically addressing this matter.

\section{Statistical analysis}

The data obtained from the questionnaire were tabulated and analyzed in GraphPad Prism version 7 (GraphPad software, San Diego, CA, USA). Because this was a descriptive study, the results are presented as the mean and percentage, and comparative tests were not performed.

\section{Results}

Ten academic leagues were found in the SBED database, and seven other leagues were identified through the active search. The questionnaire was sent exclusively to the representatives of these 17 included leagues, and all questionnaires were answered in full.

The leagues had a total of 363 student members belonging to different health courses (mean of 22.3 students/league) and distributed across all five geographic regions of Brazil (eight leagues in the Northeast, four in the Southeast, three in the South, one in the Center-West, and one in the North). The Northeast region has the highest concentration of student members (149 members) (Table 2).

Among the higher education institutions identified, 3 $(18 \%)$ have the discipline of pain in their mandatory curriculum, independent of another discipline; in 8(47\%), this discipline is mandatory but complementary to another discipline; in 1(6\%), it is offered as an elective course; and in 5(29\%), it is not part of the curriculum (Table 2).

Among the continuing education activities carried out with the participants, including classes and clinical case discussions, $65 \%$ of the leagues have a theoretical workload of $<40 \mathrm{hrs} /$ year, $29 \%$ have a theoretical workload $>40 \mathrm{hrs} /$ year ( $1 \mathrm{hr}$ per week), and $6 \%$ do not perform such activities (Table 3 ).

Care-related activities with chronic pain patients are carried out by $59 \%$ of the study leagues. Among these activities, $41 \%$ included outpatient care specializing in chronic pain; $12.5 \%$, outpatient care in other related specialties, such as neurology, rheumatology, and orthopedics; $12.5 \%$, lectures and acupuncture; and 35\%, discussions of clinical cases without patient care (Table 3).

Table 2 Description of the pain leagues by geographic region of Brazil, number of student members, affiliated educational institution and inclusion of pain teaching in the curriculum

\begin{tabular}{|c|c|c|}
\hline Region & University & Number of student members \\
\hline North & Federal University of Amazonas ${ }^{+}$ & 12 \\
\hline Northeast & $\begin{array}{l}\text { Federal University of Maranhão } \\
\text { Ceuma University* } \\
\text { State University of Maranhão } \\
\text { Federal University of Piauí } \\
\text { Faculdade Integral Diferencial }^{\circ} \\
\text { Bahia School of Medicine and Public Health } \\
\text { Federal University of Bahia }^{+} \\
\text {Mauricio de Nassau University } \\
\text { Pontifical Catholic University of Goiás* }\end{array}$ & $\begin{array}{l}34 \\
12 \\
14 \\
15 \\
16 \\
14 \\
19 \\
25 \\
16\end{array}$ \\
\hline Southeast & $\begin{array}{l}\text { Santa Marcelina College } \\
\text { University of São Paulo }{ }^{+} \\
\text {Federal University in Alfenas }{ }^{\dagger} \\
\text { Espirito Santo University Center* }\end{array}$ & $\begin{array}{l}22 \\
9 \\
46 \\
22\end{array}$ \\
\hline $\begin{array}{l}\text { South } \\
\text { Total }\end{array}$ & $\begin{array}{l}\text { State University of Maringá } \\
\text { Institute of Neurology of Curitiba }{ }^{+} \\
\text {Federal University of Health Sciences of Porto Alegre }\end{array}$ & $\begin{array}{l}40 \\
34 \\
13 \\
363\end{array}$ \\
\hline
\end{tabular}

Notes: *Mandatory and independent discipline, +Complementary to a mandatory discipline, $\dagger$ Elective course, ${ }^{\circ}$ Not in the curriculum. 
Table 3 Educational activities carried out by the leagues

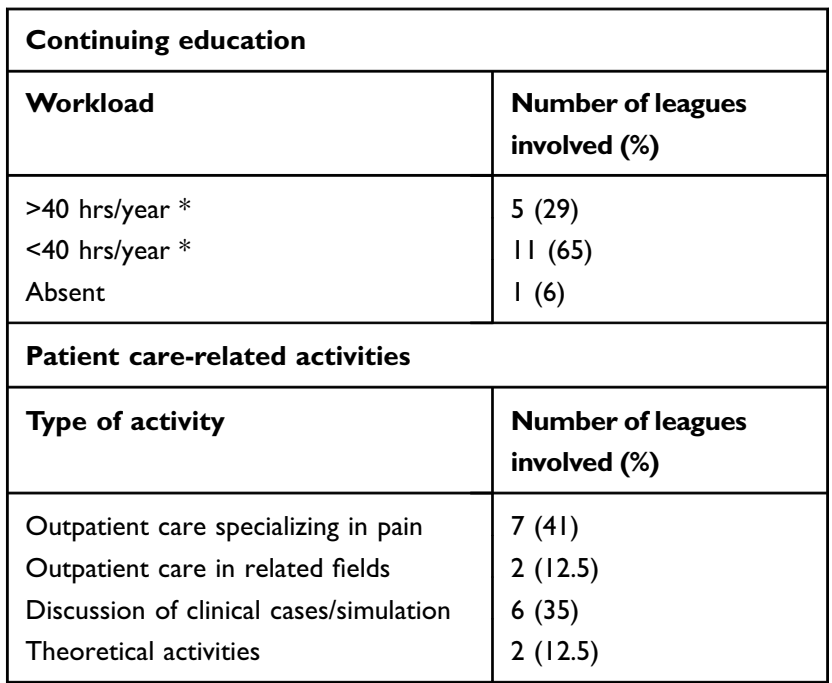

Note: *Workload of $40 \mathrm{hrs} / \mathrm{year}$ represents at least I hr of didactic activity weekly.

Twelve of the study leagues reported conducting from one to four projects in pain; three of these reported conducting between five and ten projects; and two still do not have ongoing research projects.

Regarding the participation of former academic league student members in postgraduate programs, $59 \%$ of these students are engaged in a pain research project. Similar data were obtained regarding specialization in pain after graduation, where $47 \%$ of the leagues had students that sought specialization or residency in pain after graduation (Table 4).

\section{Discussion}

The present study shows that the strategy of forming academic leagues focusing on pain education has been used in several medical teaching institutions in Brazil,

Table 4 Academic legacy of the pain leagues

\begin{tabular}{|l|l|}
\hline \multicolumn{2}{|l|}{ Former student members in postgraduate programs } \\
\hline Number of former members & Number of leagues (\%) \\
\hline $\begin{array}{l}\text { None } \\
\mathrm{I}-4\end{array}$ & $\begin{array}{l}7(4 \mathrm{I}) \\
10(59)\end{array}$ \\
\hline $\begin{array}{l}\text { Former student members in specialization/residency pro- } \\
\text { grams in pain }\end{array}$ & Number of leagues (\%) \\
\hline Number of former members & $9(53)$ \\
\hline $\begin{array}{l}\text { None } \\
\text { I-4 }\end{array}$ & $\begin{array}{l}\mathrm{I}(4) \\
5 \text { or more }\end{array}$ \\
\hline
\end{tabular}

reaching a significant number of students. Its impact on pain education can be inferred by the results presented in this article. After the students have been exposed to the activities of their leagues, over $50 \%$ engaged in postgraduation programs. Also, the same proportion chose to specialize in pain medicine.

Among the universities to which the leagues in this study are affiliated, only $8(18 \%)$ offer a discipline dedicated specifically to the study of pain, while in $5(29 \%)$ pain is not part of the curriculum, highlighting disability in pain education in our country. Other developing countries face a similar situation to that in Brazil. ${ }^{9}$ However, the insufficiency of pain education is not a problem exclusive to developing countries, as this issue is also being discussed in developed countries. ${ }^{16-19}$

A survey conducted at universities in the United Kingdom showed that pain-related content averaged only $12 \mathrm{hrs}$ in the curriculum of health students and mostly comprises theoretical classes (87\%). Of the 74 programs evaluated in the study, only $11(14.8 \%)$ had an available course exclusively on pain, of which nine were elective and only two used the curriculum recommended by IASP. $^{20}$ An internal study conducted with medical students at the University of Washington showed that $77 \%$ of students considered their pain education to be inadequate, and only $15 \%$ considered their clinical education for managing pain patients sufficient. ${ }^{21}$

In addition to curricular barriers, inadequate professor training, lack of confidence in the effectiveness of pain education, and lack of opportunities for education in different specialties are also identified as obstacles to pain education in developed countries. ${ }^{22}$ In a study at the University of Helsinki, the students interviewed demonstrated empathy for patients with chronic pain when reporting anxiety in witnessing the suffering of these patients, as well as a greater propensity to prescribe opioids for cancer patients. Students also find it difficult for patients with chronic pain to receive adequate treatment, and more than $30 \%$ of the respondents agreed that these patients should be treated by pain specialists. ${ }^{23}$ The results obtained in that study can be explained by the absence of formal education in pain at that university. In general, students present a positive attitude toward pain education and perceive the limitations of their learning. ${ }^{16,17,23,24}$

In Brazil, the inadequacy of curricula with regard to pain education prompted the creation of study groups composed of students and professors that evolved to the 
formation of the ALPs, whose objectives were to stimulate study of pain and to engage students in care-related and research activities. ${ }^{13,15}$ In other countries, other strategies have been adopted to reduce gaps in the training of health professionals; $;^{9,18,21}$ however, none of them are similar to those described in this study. In a study conducted at McGill University in Canada, patients, students, and professors were interviewed regarding their perception of the quality of pain education. The authors concluded that training in pain for students was inadequate and highlighted issues to be addressed in order to correct the learning deficit, such as pain assessment, treatment of pain, patient-centered pain management, ethical aspects of the care of pain patients, and adjusting the curriculum to emphasize pain. The results found in that study contributed to the construction of an electronic tool developed to aid teaching through case simulation on an online platform. ${ }^{18}$ In response to the study discussed earlier, the University of Washington also instituted changes in its curricular structure, increasing the mandatory teaching time of pain from 6 to $24 \mathrm{hrs}$ and expanding the program of elective courses from 177 to $318 \mathrm{hrs}^{21}$

In the USA, the dissemination of pain education has also occurred through the creation of multidisciplinary fellowship programs for graduates to train specialists in pain medicine. $^{25}$ A different approach was tested at two Canadian universities, at which short-term multidisciplinary courses for pain teaching were conducted, and that resulted in positive evaluations by participants regarding personal satisfaction and knowledge gain, as well as a greater understanding of the role of other health fields in the treatment of pain. ${ }^{26}$ Another recent strategy to encourage pain education is the Global Year for Excellence in Pain Education, an IASP initiative to bridge the gap between what is known about the subject and what is being done to address it. ${ }^{27}$

Among the activities carried out by the Brazilian pain leagues, teaching has great importance, and of the 17 leagues surveyed, 16 (94\%) have adopted continuing education programs, and five (29\%) have workloads of more than $1 \mathrm{hr}$ per week. Considering, for example, the average workload found in the United Kingdom study, in just 3 months the students participating in the leagues studied would be exposed to the same number of hours offered to the UK students throughout the entire curriculum. ${ }^{16}$

In this same British study, it was shown that most of the subjects related to pain were discussed only in the classroom environment (6), which differs greatly from the data obtained from the academic leagues, which, for the most part (53\%), offer care-related activities in a specialty outpatient clinic. It gives students the opportunity to manage real patients under the supervision of a fieldspecific professor and to be exposed to the challenges involved in pain treatment.

The Advancing the Provision of Pain Education and Learning (APPEAL) study showed that in European countries, pain was addressed in medical schools' curriculums within compulsory nonpain-specific modules in $55 \%$ of the schools and via a dedicated pain module in $33 \%$ of them. In $7 \%$ of the studied courses, pain teaching was distributed through the curriculum, instead of specific modules, and $7 \%$ of the curriculums did not present evidence of pain education. ${ }^{20}$ As an attempt to remedy this situation, the committee of DGSS (Deutsche Gesellschaft zum Studium des Schmerzes), the German chapter of the IASP, proposed that pain management became a mandatory subject for undergraduate medical students, and this policy was implemented in 2012. ${ }^{28,29}$ After that, in 2013, the committee on education of the European Federation of IASP chapters (EFIC) proposed a unified pain management core curriculum for all European medical schools that consisted of basic knowledge necessary for general clinicians be able to approach the most common pain conditions. ${ }^{29}$

In addition, $88 \%$ of the leagues studied have students engaged in research projects, and in almost $60 \%$ of the cases, at least one student is attending a pain-related graduate program. The experience described in review studies of other academic leagues focused on different health fields reinforces the propensity of these initiatives toward the development of scientific research and outreach activities. ${ }^{4,30}$

This study has some limitations. The analyzed data were obtained from a questionnaire answered only by the person in charge of each league. This choice was made to obtain information regarding former members, number of research projects, and other activities, which would not be known to members who were not occupying an administrative position. Although the studied ALPs are distributed in all Brazilian geographic regions, they are concentrated in 17 universities, which represents only a portion of the medical teaching institutions in the country. However, academic leagues are seen as a strategy with good acceptance by the regional scientific community, low cost of implementation, easy reproducibility and with production of measurable results in improving the quality of pain education of its participants.

In our study, it became clear that some key points are necessary to improve pain education in Brazil and 
worldwide. First of all, students that participated in the leagues had a greater amount of exposure to content related to pain. Second, they were encouraged to engage in supervised activities with real patients, where they were able to improve their abilities. Finally, the early start in pain research is also very relevant in ALPs. The Brazilian experience shows that it is possible to address these curricular deficiencies in pain education through a strategy not well known in other countries, that trains professionals capable of dealing with patients in acute and chronic pain and engaged in scientific research and knowledge production.

The ALPs have produced very interesting results, but these initiatives still depend on students' willingness to organize, to attract professors who may be willing to devote their time to the league and overcome barriers, such as the burocracy to obtain funding. All these obstacles contribute to a very fragile environment to the perpetuation of the leagues. One solution to the current scenario would be to change the passive role that universities have played so far, and to take steps to encourage the dissemination of academic leagues as formalized extracurricular activities.

\section{Conclusion}

This study demonstrated the importance of academic leagues in pain management training of Brazilian health care students through theoretical and practical teaching activities, given the recognized curricular deficiency in pain education. The exposure of students to league activities seems to arouse greater interest in a specialization or residency in pain. Moreover, the leagues also seem to be a bridge between scientific initiation among undergraduate students and the progression of these students toward postgraduate programs.

\section{Disclosure}

The authors report no conflicts of interest in this work.

\section{References}

1. Blyth FM. The global burden of neuropathic pain. Pain. 2018;159 (3):614-617. doi:10.1097/j.pain.0000000000001127

2. Kassebaum NJ, Bertozzi-Villa A, Coggeshall MS, et al. Global, regional, and national levels and causes of maternal mortality during 19902013: a systematic analysis for the Global Burden of Disease Study 2013. Lancet. 2014;384(9947):980-1004. doi:10.1016/S0140-6736 (14)60696-6

3. Racine M, Dion D, Dupuis G, et al. The canadian STOP-PAIN project: the burden of chronic pain - Does sex really matter? Clin J Pain 2014;30(5):443-452. doi:10.1097/AJP.0b013e3182a0de5e
4. Rice ASC, Smith BH, Blyth FM. Pain and the global burden of disease. Pain. 2016;157(4):791-796. doi:10.1097/j.pain.00000000 00000454

5. Wilkinson P, Watt-Watson J The gap between knowledge and practice. Fact Sheet No1. IASP fact sheets on pain education; 2018. Available from: http://s3.amazonaws.com/rdcms-iasp/files/produc tion/public/globalyear/1_Gap_Between_Knowledge_and_Practice_ EnglishFINAL.pdf?utm_source=iaspwebsite\&utm_medium $=$ globa lyear\&utm_campaign $=2018$ globalyear-factsheets-english. Accessed April 29, 2018.

6. de Souza JB, Grossmann E, Perissinotti DMN, de Oliveira Junior JO, Da Fonseca PRB, de Posso IP. Prevalence of chronic pain, treatments, perception, and interference on life activities: Brazilian populationbased survey. Pain Res Manag. 2017;2017:1-9. doi:10.1155/2017/ 4643830

7. García CA, Santos Garcia JB, Del Rosario Berenguel Cook M, et al. Undertreatment of pain and low use of opioids in Latin America. Pain Manag. 2018;8(3):181-196. doi:10.2217/pmt-2017-0043

8. Dahlhamer J, Lucas J, Zelaya C, et al. Prevalence of chronic pain and high-impact chronic pain among adults - United States, 2016. MMWR Morb Mortal Wkly Rep. 2018;67(36):1001-1006. doi:10.15585/ mmwr.mm6736a2

9. Bond M. Pain education issues in developing countries and responses to them by the International Association for the Study of Pain. Pain Res Manag. 2011;16(6):404-406.

10. Dalpai D, Mendes FF, Asmar JAVN, Carvalho PL, Loro FL, Branco A. Pain and palliative care: the knowledge of medical students and the graduation gaps. Rev Dor. 2017;18(4):307-310. doi:10.5935/ 1806-0013.20170120

11. Sociedade Brasileira para o Estudo da Dor (SBED). Brasil sem dor Campanha nacional pelo tratamento e controle da dor aguda e crônica; 2018.

12. Alves S, Silva D, Flores O. Academic leagues in student training. Rev Bras Educ Med. 2015;39(3):410-425.

13. Goergen DI. Academic leagues: a review of many experiences. Arq Catarin Med. 2017;46(3):183-193. doi:10.1590/S0482-50042011 000100006

14. Suelen A, Cavalcante P. As Ligas Acadêmicas na Área da Saúde: lacunas do Conhecimento na Produção Científica Brasileira. Rev Bras Educ Med. 2018;42(1):197-204. doi:10.1590/1981-52712018v42n1 RB20170081

15. Pego-Fernandes PM, Mariani AW. O ensino médico além da graduação: ligas acadêmicas. Sao Paulo Med J. 2010;128(5):257258. doi: $10.1590 / \mathrm{S} 1516-31802010000500002$

16. Briggs EV, Carr ECJ, Whittaker MS. Survey of undergraduate pain curricula for healthcare professionals in the United Kingdom. Eur $J$ Pain. 2011;15(8):789-795. doi:10.1016/j.ejpain.2011.01.006

17. Mezei L, Murinson BB. Pain education in North American Medical Schools. J Pain. 2011;12(12):1199-1208. doi:10.1016/j.jpain.2011. 06.006

18. Tellier -P-P, Bélanger E, Rodríguez C, Ware MA, Nancy PN. Improving undergraduate medical education about pain assessment and management: A qualitative descriptive study of stakeholders' perceptions. Pain Res Manag. 2013;18(5):259-265.

19. Watt-Watson J, McGillion M, Hunter J, et al. A survey of prelicensure pain curricula in health science faculties in Canadian universities. Pain Res Manag. 2009;14(6):439-444. doi:10.1155/2009/307932

20. Briggs EV, Battelli D, Gordon D, et al. Current pain education within undergraduate medical studies across Europe: Advancing the Provision of Pain Education and Learning (APPEAL) study. BMJ Open. 2015;5(8):e006984. doi:10.1136/bmjopen-2014-006984

21. Tauben DJ, Loeser JD. Pain education at the University of Washington School of Medicine. J Pain. 2013;14(5):431-437. doi:10.1016/j.jpain.2013.01.005

22. Watt-Watson J, Murinson BB. Current challenges in pain education. Pain Manag. 2013;3(5):351-357. doi:10.2217/pmt.13.39 
23. Niemi-Murola L, Nieminen JT, Kalso E, Pöyhiä R. Medical undergraduate students' beliefs and attitudes toward pain - How do they mature? Eur J Pain. 2007;11(6):700-706. doi:10.1016/j.ejpain.2006.12.001

24. Argyra E, Siafaka I, Moutzouri A, et al. How does an undergraduate pain course influence future physicians' awareness of chronic pain concepts? A comparative study. Pain Med. 2015;16(2):301-311. doi:10.1111/ pme. 12568

25. Huntoon E. Education and training of pain medicine specialists in the United States. Eur J Phys Rehabil Med. 2013;49(1):103-106.

26. Hadjistavropoulos HD, Juckes K, Dirkse D, et al. Student evaluations of an interprofessional education experience in pain management. $J$ Interprof Care. 2015;29(1):73-75. doi:10.3109/13561820.2014.917613

27. IASP. 2018 Global Year for Excellence in Pain Education; 2018. IASP. Available from: https://www.iasp-pain.org/GlobalYear. Accessed April 23, 2018.
28. Kopf A, Dusch M, Alt-Epping B, Petzke F, Treede R-D. [Pain medicine as a cross-sectional subject in German medical schools. An opportunity for general pain management]. Der Schmerz. 2014;28(4):405-413. doi:10.1007/s00482-014-1433-3

29. Committee on Education of the European Federation of IASP Chapters. The pain management core curriculum for German Medical Schools. Committee on Education of the European Federation of IASP Chapters. Available from: https://www.european painfederation.eu/w p-content/uploads/2016/12/ CoreCurriculumPainManagement-EFIC-June-2013_FINAL.pdf. 2013. Accessed July 29, 2018.

30. Ferreira DAV, Aranha RN, Ornellas MHF. Academic Leagues: a student proposal for teaching, research and extension. Interagir Pensando a Extensão. 2011;16:47-51. doi:10.12957/interag. 2011.5334

\section{Publish your work in this journal}

The Journal of Pain Research is an international, peer reviewed, open access, online journal that welcomes laboratory and clinical findings in the fields of pain research and the prevention and management of pain. Original research, reviews, symposium reports, hypothesis formation and commentaries are all considered for publication. The manuscript management system is completely online and includes a very quick and fair peer-review system, which is all easy to use. Visit http:// www.dovepress.com/testimonials.php to read real quotes from published authors. 